\title{
Targeting Toxic Nuclear RNA Foci \\ with CRISPR-Cas13 \\ to Treat Myotonic Dystrophy
} Pornthida Poosala ${ }^{1,2}$, Sean R. Lindley ${ }^{1,2}$, Kelly M. Anderson
Anderson
An,

${ }^{1}$ Center for RNA Biology, ${ }^{2}$ Aab Cardiovascular Research Institute, University of Rochester

School of Medicine and Dentistry, Rochester, New York, U.S.A., 14642

${ }^{*}$ Corresponding Author:

Douglas M. Anderson: doug_anderson@urmc.rochester.edu

Keywords: DMPK, DM1, CUG, trinucleotide repeat, microsatellite expansion, RNA Foci,

MBNL1, muscleblind-like 1, dPspCas13b, crRNA, hilightR, eraseR 
Human monogenetic diseases can arise from the aberrant expansion of tandem nucleotide repeat sequences, which when transcribed into RNA, can misfold and aggregate into toxic nuclear foci ${ }^{1}$. Nuclear retention of repeat-containing RNAs can disrupt their normal expression and induce widespread splicing defects by sequestering essential RNA binding proteins. Among the most prevalent of these disorders is myotonic dystrophy type 1 (DM1), a disease occurring from the expression of a noncoding CTG repeat expansion in the 3'UTR of the human dystrophia myotonica protein kinase (DMPK) gene $\mathrm{e}^{2,3}$. Here we show that RNAbinding CRISPR-Cas13, with a robust non-classical nuclear localization signal, can be efficiently targeted to toxic nuclear RNA foci for either visualization or cleavage, tools we named hilight $R$ and erase $R$, respectively. Hilight $R$ combines catalytically dead Cas13b (dCas13b) with a fluorescent protein to directly visualize CUG repeat RNA foci in the nucleus of live cells, allowing for quantification of foci number and observation of foci dynamics. Erase $R$ utilizes the intrinsic endoribonuclease activity of Cas13b, targeted to nuclear CUG repeat RNA, to disrupt nuclear foci. These studies demonstrate the potential for targeting toxic nuclear RNA foci directly with CRISPR-Cas13 for either the identification or treatment of DM1. The efficient and sequence programmable nature of CRISPR-Cas13 systems will allow for rapid targeting and manipulation of other human nuclear RNA disorders, without the associated risks of genome editing.

Myotonic dystrophy type 1 (DM1) is an autosomal dominant human monogenic disease characterized by progressive myotonia, muscle wasting, cardiac arrhythmias, and cognitive dysfunction ${ }^{4}$. DM1 is the most common form of adult-onset muscular 
dystrophy, occurring in roughly 1 in 8,000 individuals ${ }^{5}$. Mutant DMPK mRNAs with greater than $\sim 50$ CUG repeats form toxic nuclear RNA foci, which prevent normal DMPK expression and induce widespread defects in alternative splicing and polyadenylation by sequestering members of the muscleblind-like (MBNL) family of RNA binding proteins ${ }^{6-}$ ${ }^{13}$. Loss of MBNL1 and 2 function account for up to $80 \%$ of the observed DM1 phenotype, however, overexpression of MBNL proteins have had limited success rescuing splicing defects and only modest amelioration of muscle function in DM1 mouse models, suggesting a multifactorial cause for DM1 symptoms ${ }^{14-17}$. The multitude of dysfunctional pathologies associated with the formation of toxic RNA foci suggests that targeted degradation of CUG expansion (CUG ${ }^{\exp }$ ) RNA would provide therapeutic benefit to DM1 patients.

Despite intense effort, there are no currently approved therapies designed to treat DM1. Antisense oligonucleotides (ASOs) targeting CUG-repeats have been successfully used to reduce the levels of toxic RNAs and disrupt binding and sequestration of MBNL proteins in animal models ${ }^{18,19}$. However, significant challenges remain for the delivery of these molecules at therapeutically effective levels in human skeletal muscle. Genome editing approaches using CRISPR-Cas9 DNA endonucleases have been employed to directly edit the DMPK gene locus. However, CRISPR-Cas9 editing at either the 5' or 3' ends of CTG genomic repeats can induce large and uncontrolled sequence deletions, and the use of double guide-RNAs flanking the repeat expansion can lead to frequent sequence inversions, which remain toxic ${ }^{20,21}$. Since CRISPR-Cas9 approaches for manipulating DNA remain inefficient and controversial due to the risk of germline editing, an alternative approach targeting the repeat RNAs using deactivated Cas9 (dCas9) fused 
to an active ribonuclease has recently been shown to be effective in cells ${ }^{22}$. However, the efficiency of this approach for targeting nuclear CUG ${ }^{\text {exp }}$ RNA in DM1 patients could be limited by a number of factors, such as: 1) dCas9 retains affinity for DNA, which could compete for its binding to RNA, 2) the large size of dCas9 fusion proteins may limit their nuclear localization or delivery in vivo, 3) dCas9 utilizes short guide-RNAs which may increase the chance of off-target RNA cleavage and, 4) they require protospacer adjacent motifs (PAM) for efficient binding, which are not present in most human repeat expansion sequences. Thus, significant challenges remain for the development of efficient therapeutic strategies to target toxic nuclear RNAs in DM1 patients.

In contrast, bacterial-derived CRISPR-Cas13 systems bind specifically to RNA and function as endoribonucleases to cleave RNA, bypassing the risk of germline editing that is associated with DNA-binding CRISPR-Cas endonucleases ${ }^{23-25}$. Single residue mutations within the two nuclease domains of Cas13 generate a catalytically deactivated enzyme (dCas13), which retains programmable RNA binding affinity in mammalian systems without the requirement for PAM sequences for efficient targeting ${ }^{26}$. Due to their large size and lack of intrinsic localization signals, both Cas9 and Cas13 fusion proteins are inefficiently localized to the mammalian nucleus. In our recent pre-print manuscript describing the adaptation of CRISPR-Cas13 for inducing targeted RNA cleavage and polyadenylation (https://doi.org/10.1101/531111), we identified a non-classical nuclear localization signal (NLS) derived from the yeast Ty1 retrotransposon which promotes robust nuclear localization of Cas13. The powerful activity of the Ty1 NLS suggested that efficient targeting of nuclear RNAs could be achieved for either visualization or cleavage using CRISPR-Cas13. 
To visualize nuclear RNAs using CRISPR-Cas13, we designed a fusion protein combining the catalytically dead Type VI-B Cas13b enzyme from Prevotella sp. P5125 (dPspCas13b) with either a C-terminal enhanced Green Fluorescent Protein (eGFP) or red fluorescent protein, mCherry (Figure 1A). A 3x FLAG epitope tag (F) and Ty1 nuclear localization sequence (Ty1 NLS) were added to the N-terminus of the dPspCas13b fusion proteins to promote efficient nuclear localization, hereinafter referred to as hilightR green or hilightR red (Figure 1A). Toxic RNA foci are the cellular hallmark of DM1 and can be induced in many cell types by the expression of transgenes expressing expanded CUG repeats. To mimic the nuclear RNA foci found in patients with DM1, we utilized a vector containing 960 CUG repeats in the human DMPK 3' UTR (DT960) (Figure 1B) $)^{27}$. The DT960 construct is sufficient to recapitulate RNA foci formation in cells and can be detected by Fluorescent In Situ Hybridization (FISH) using an antisense (CAG) repeat probe or with an mCherry-MBNL1 fusion protein (Supplementary Figures $1 \mathrm{~A}$ and B). To target hilightR fusion proteins to CUG repeats, we designed a PspCas13bcompatible crRNA containing an antisense CAG repeat target sequence (CAGx9), which is predicted to hybridize with 9 CUG repeats (Figure 1C). Guided by the CAGx9 repeat crRNA, hilightR green and red were completely nuclear localized and highlighted nuclear RNA foci generated by the DT960 vector (Figure 1D and Supplementary Figure 1C). In contrast, co-expression of hilightR constructs with a non-targeting crRNA resulted in broad, un-localized nuclear fluorescence (Figure 1D and Supplementary Figure 1C).

Nuclear foci labeled with hilightR green co-localized with an Alexa Fluor 488conjugated CAG oligonucleotide probe (AF488-CAGx7), detected using FISH (Figure 2A). Consistent with previous reports, nuclear foci labeled with hilightR green co-localized 
with MBNL1 protein, detected using an mCherry-MBNL1 fusion protein, and partially colocalized with splicing speckles, detected with an antibody specific for SC-35 (Figure 2B and Supplementary Figure 2). These results demonstrate that hilightR accurately targets CUG $^{\exp }$ RNA foci.

The efficient nuclear targeting of CRISPR-Cas13 to CUG ${ }^{\text {exp }}$ RNA foci suggested it could be a useful for targeted cleavage of toxic CUG ${ }^{\text {exp }}$ RNA, using its inherent endoribonuclease activity. Cas13 has been shown to be useful for specific cleavage of mRNA transcripts in mammalian and plant cells ${ }^{26,28,29}$. To determine if Cas 13 endoribonuclease activity is sufficient to cleave $C U G^{\exp }$ RNA foci, we modified the hilightR green fusion protein by reactivating PspCas13b's catalytic mutations using site directed mutagenesis. Surprisingly, we found that activated hilightR green did not significantly reduce the number of RNA foci using the CAGx9 targeting crRNA, compared with a nontargeting guide-RNA (data not shown). However, activated PspCas13b containing the Nterminal Ty1 NLS, but lacking the C-terminal eGFP (herein referred to as eraseR), resulted in a significant reduction in the number and intensity of RNA foci, quantified using an mCherry-MBNL1 fusion protein (Figure 3A and B). Since target site flanking sequences can influence Cas13 nuclease activation, we tested CAGx9 crRNAs in two other reading frames (CAGx9-f2 and CAGx9-f3). EraseR guided by all three CAGx9 crRNAs resulted in significant reduction in the number and intensity of RNA foci per cell, compared to a non-targeting crRNA (Figure 3A and B). Additionally, catalytically dead PspCas13b containing an N-terminal Ty1 NLS and lacking the C-terminal eGFP did not significantly reduce the number and intensity of RNA foci, quantified using an mCherry 
MBNL1 fusion protein (Supplementary Figure 3). These date demonstrate for the first time that CRISPR-Cas13 is sufficient to degrade CUG ${ }^{\exp }$ RNA foci.

While there are currently no available treatments for myotonic dystrophies or other human RNA repeat expansion disorders, the rapid development of CRISPR-Cas13 systems offer hope that targeted approaches to treat DM1 will soon be achievable. We have shown that Cas13b, localized by a powerful non-classical Ty1 NLS, can be used to efficiently target nuclear $\mathrm{CUG}^{\mathrm{exp}}$ RNA foci for either visualization or targeted degradation in mammalian cells. The NLS used in these studies was derived from the yeast Ty1 LTRretrotransposon (Ty1 NLS), which replicates its genome through a cytoplasmic intermediate ${ }^{30}$. As opposed to higher eukaryotes in which the nuclear envelope breaks down during cell division, the nuclear envelope in yeast remains intact during cell division and thus Ty1 requires active nuclear import for retrotransposition ${ }^{31}$. Interestingly, quiescent mammalian cells also retain a nuclear envelope, suggesting that the Ty1 NLS may be useful for targeting nuclear RNAs by Cas proteins in non-dividing cells.

The programmable nature of CRISPR-Cas13, through simple modification of crRNA target sequences, allow hilightR and erase $R$ to be easily adapted for the study and cleavage of other nuclear RNAs, or other repeat expansion disorders such as myotonic dystrophy type 2 (DM2), amyotrophic lateral sclerosis (ALS), huntington's disease-like 2 (HDL2), spinocerebellar ataxias 8, 31 and 10 (SCA8, -31, -10) and fragile X-associated tremor ataxia syndrome (FXTAS). As with other approaches (ASOs or CRISPR-Cas) targeted to simple repeat sequences, there remains the potential for 'coincidental' cleavage of other human mRNA transcripts which contain these short repeat sequence motifs. Future studies will be necessary to evaluate any potential deleterious impacts 
resulting from coincidental cleavage events. Alternatively, directly targeting unique human DMPK transcript sequences for degradation by CRISPR-Cas13 or by other forms of RNA manipulation may offer additional approaches for the treatment of toxic RNA diseases.

\section{REFERENCES}

1 Wojciechowska, M. \& Krzyzosiak, W. J. Cellular toxicity of expanded RNA repeats: focus on RNA foci. Hum Mol Genet 20, 3811-3821, doi:10.1093/hmg/ddr299 (2011).

$2 \mathrm{Fu}, \mathrm{Y} . \mathrm{H}$. et al. An unstable triplet repeat in a gene related to myotonic muscular dystrophy. Science 255, 1256-1258 (1992).

3 Mahadevan, M. et al. Myotonic dystrophy mutation: an unstable CTG repeat in the 3' untranslated region of the gene. Science 255, 1253-1255 (1992).

4 Bird, T. D. in GeneReviews((R)) (eds M. P. Adam et al.) (1993).

$5 \quad$ Harper, P. S., Brook, J. D. \& Newman, E. Myotonic dystrophy. 3rd edn, (Saunders, 2001).

6 Nakamori, M. et al. Splicing biomarkers of disease severity in myotonic dystrophy. Ann Neurol 74, 862-872, doi:10.1002/ana.23992 (2013).

7 Kuyumcu-Martinez, N. M. \& Cooper, T. A. Misregulation of alternative splicing causes pathogenesis in myotonic dystrophy. Prog Mol Subcell Biol 44, 133-159 (2006).

8 Batra, R. et al. Loss of MBNL leads to disruption of developmentally regulated alternative polyadenylation in RNA-mediated disease. Mol Cell 56, 311-322, doi:10.1016/j.molcel.2014.08.027 (2014).

9 Brook, J. D. et al. Molecular basis of myotonic dystrophy: expansion of a trinucleotide (CTG) repeat at the $3^{\prime}$ end of a transcript encoding a protein kinase family member. Cell 68, 799-808 (1992). 
10 Martorell, L., Monckton, D. G., Sanchez, A., Lopez De Munain, A. \& Baiget, M. Frequency and stability of the myotonic dystrophy type 1 premutation. Neurology 56, 328-335 (2001).

11 Harley, H. G. et al. Size of the unstable CTG repeat sequence in relation to phenotype and parental transmission in myotonic dystrophy. Am J Hum Genet 52, 1164-1174 (1993).

12 Mankodi, A. et al. Muscleblind localizes to nuclear foci of aberrant RNA in myotonic dystrophy types 1 and 2. Hum Mol Genet 10, 2165-2170 (2001).

13 Taneja, K. L., McCurrach, M., Schalling, M., Housman, D. \& Singer, R. H. Foci of trinucleotide repeat transcripts in nuclei of myotonic dystrophy cells and tissues. $J$ Cell Biol 128, 995-1002 (1995).

14 Kanadia, R. N. et al. A muscleblind knockout model for myotonic dystrophy. Science 302, 1978-1980, doi:10.1126/science.1088583 (2003).

15 Lee, K. Y. et al. Compound loss of muscleblind-like function in myotonic dystrophy. EMBO Mol Med 5, 1887-1900, doi:10.1002/emmm.201303275 (2013).

16 Yadava, R. S. et al. MBNL1 overexpression is not sufficient to rescue the phenotypes in a mouse model of RNA toxicity. Hum Mol Genet, doi:10.1093/hmg/ddz065 (2019).

17 Kanadia, R. N. et al. Reversal of RNA missplicing and myotonia after muscleblind overexpression in a mouse poly(CUG) model for myotonic dystrophy. Proc Natl Acad Sci U S A 103, 11748-11753, doi:10.1073/pnas.0604970103 (2006).

18 Jauvin, D. et al. Targeting DMPK with Antisense Oligonucleotide Improves Muscle Strength in Myotonic Dystrophy Type 1 Mice. Mol Ther Nucleic Acids 7, 465-474, doi:10.1016/j.omtn.2017.05.007 (2017).

19 Wheeler, T. M. et al. Targeting nuclear RNA for in vivo correction of myotonic dystrophy. Nature 488, 111-115, doi:10.1038/nature11362 (2012).

20 van Agtmaal, E. L. et al. CRISPR/Cas9-Induced (CTGCAG)n Repeat Instability in the Myotonic Dystrophy Type 1 Locus: Implications for Therapeutic Genome Editing. Mol Ther 25, 24-43, doi:10.1016/j.ymthe.2016.10.014 (2017). 
21 Wang, Y. et al. Therapeutic Genome Editing for Myotonic Dystrophy Type 1 Using CRISPR/Cas9. Mol Ther 26, 2617-2630, doi:10.1016/j.ymthe.2018.09.003 (2018).

22 Batra, R. et al. Elimination of Toxic Microsatellite Repeat Expansion RNA by RNATargeting Cas9. Cell 170, 899-912 e810, doi:10.1016/j.cell.2017.07.010 (2017).

23 Abudayyeh, O. O. et al. C2c2 is a single-component programmable RNA-guided RNAtargeting CRISPR effector. Science 353, aaf5573, doi:10.1126/science.aaf5573 (2016).

24 Smargon, A. A. et al. Cas13b is a Type VI-B CRISPR-Associated RNA-Guided RNase Differentially Regulated by Accessory Proteins Csx27 and Csx28. Mol Cell 65, 618-630 e617, doi:10.1016/j.molcel.2016.12.023 (2017).

25 East-Seletsky, A., O'Connell, M. R., Burstein, D., Knott, G. J. \& Doudna, J. A. RNA Targeting by Functionally Orthogonal Type VI-A CRISPR-Cas Enzymes. Mol Cell 66, 373383 e373, doi:10.1016/j.molcel.2017.04.008 (2017).

26 Cox, D. B. T. et al. RNA editing with CRISPR-Cas13. Science 358, 1019-1027, doi:10.1126/science.aaq0180 (2017).

27 Ho, T. H. et al. Muscleblind proteins regulate alternative splicing. EMBO J 23, 3103-3112, doi:10.1038/sj.emboj.7600300 (2004).

28 Abudayyeh, O. O. et al. RNA targeting with CRISPR-Cas13. Nature 550, 280-284, doi:10.1038/nature24049 (2017).

29 Aman, R. et al. RNA virus interference via CRISPR/Cas13a system in plants. Genome Biol 19, 1, doi:10.1186/s13059-017-1381-1 (2018).

30 Curcio, M. J., Lutz, S. \& Lesage, P. The Ty1 LTR-Retrotransposon of Budding Yeast, Saccharomyces cerevisiae. Microbiol Spectr 3, MDNA3-0053-2014, doi:10.1128/microbiolspec.MDNA3-0053-2014 (2015).

31 Moore, S. P., Rinckel, L. A. \& Garfinkel, D. J. A Ty1 integrase nuclear localization signal required for retrotransposition. Mol Cell Biol 18, 1105-1114 (1998). 
32 Anderson, D. M. et al. Severe muscle wasting and denervation in mice lacking the RNAbinding protein ZFP106. Proc Natl Acad Sci $U S$ A 113, E4494-4503, doi:10.1073/pnas.1608423113 (2016).

\section{ACKNOWLEDGEMENTS}

DT960 was a gift from Thomas Cooper (Addgene plasmid \# 80412; http://n2t.net/addgene:80412; RRID: Addgene_80412).

\section{AUTHOR CONTRIBUTIONS}

P.P., K.M.A. and D.M.A. designed the experiments. P.P., S.R.L, K.M.A., and D.M.A performed the experiments and analyzed data. P.P., K.M.A., and D.M.A generated the figures and wrote the manuscript.

\section{AUTHOR INFORMATION}

The authors declare no competing financial interests. Correspondence and requests for materials should be addressed to D.M.A. (doug_anderson@urmc.rochester.edu). 


\section{FIGURE LEGENDS}

Figure 1 Development of robust nuclear localized CRISPR-Cas 13 fusion proteins for the visualization of toxic RNA foci. (A) Design of catalytically dead PspCas13b (dPspCas13b) encoding an N-terminal 3x FLAG and Ty1 NLS and C-terminal eGFP. F - 3xFLAG epitope; NLS - Ty1 nuclear localization sequence; pA - SV40 polyadenylation sequence. (B) Diagram depicting the DT960 vector, which expresses a C-terminal genomic fragment of human DMPK (exons 11-15) encoding a 960 CTG repeat expansion in the 3'UTR. (C) Design of the CAGx9 crRNA and it's predicted hybridization with CUG ${ }^{\exp }$ RNA. (D) Representative images showing the cellular localization of hilightR green guided by either a non-targeting crRNA or the CAGx9 crRNA in COS7 cells expressing CUG ${ }^{\exp }$ RNA. Scale bars, $10 \mu \mathrm{m}$.

Figure 2 Co-localization of hilightR green with CUG ${ }^{\exp }$ RNA foci and MBNL1. (A) Immunohistochemistry using an anti-FLAG antibody was used to detect hilightR red, targeted with the CAGx9 crRNA, which co-localized with CUG ${ }^{\exp }$ RNA detected by FISH with an Alexa Fluor 488 CAGx7 probe. (B) HilightR green co-localized with mCherryMBNL1 in COS7 cells expressing CUG ${ }^{\text {exp }}$ RNA foci when targeted with the CAGx9 crRNA, but not with a non-targeting crRNA. Scale bars, $10 \mu \mathrm{m}$.

Figure 3 Degradation of toxic RNA foci by catalytically active PspCas13b. (A) Coexpression of active PspCas13b encoding a Ty1 NLS (eraseR) significantly decreased the number of RNA foci in cells expressing CUG ${ }^{\exp }$ RNA, when targeted with all three 
CAGx9 crRNAs, detected using mCherry-MBNL1. (B) Representative micrographs of cells targeted by erase $R$ showing foci detected by mCherry-MBNL1, which are significantly decreased in number and appear fainter. Scale bars, $10 \mu \mathrm{m} .{ }^{* *}=p$-value $<$ $0.01,{ }^{* * *}=p$-value $<0.001,{ }^{* * *}=p$-value $<0.0001$ 
bioRxiv preprint doi: https://doi.org/10.1101/716514; this version posted July 26,2019 . The copyright holder for this preprint (which was not certified by peer review) is the author/funder, who has granted bioRxiv a license to display the preprint in perpetuity. It is made available under aCC-BY-NC 4.0 International license.

\section{FIGURES}

A

hilightR green

CMV

B

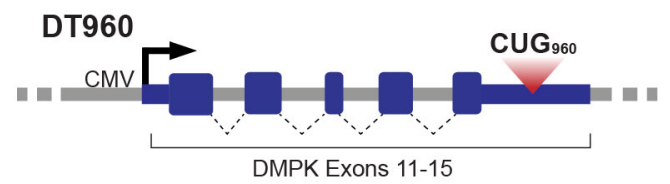

C

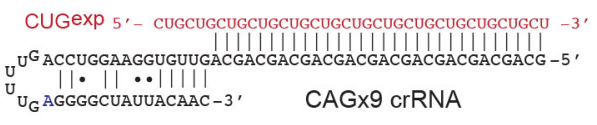

D

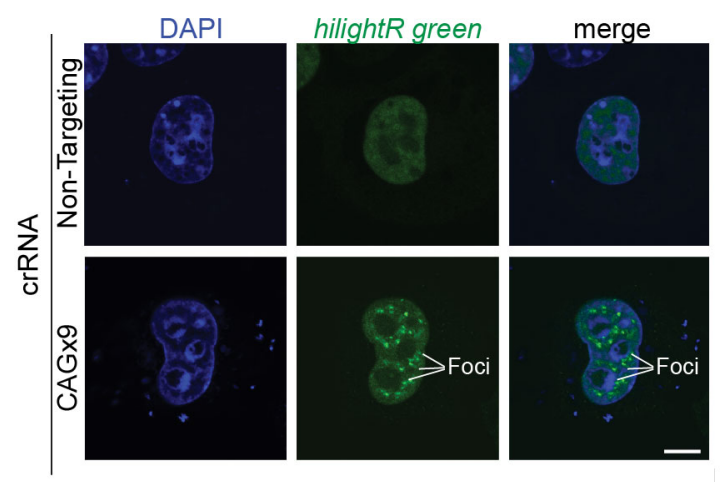

Figure 1 
bioRxiv preprint doi: https://doi.org/10.1101/716514; this version posted July 26, 2019. The copyright holder for this preprint (which was not certified by peer review) is the author/funder, who has granted bioRxiv a license to display the preprint in perpetuity. It is made available under aCC-BY-NC 4.0 International license.

A

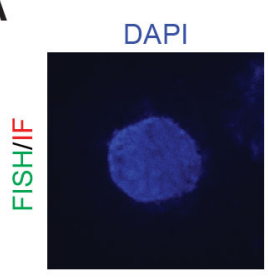

$\alpha-F L A G$
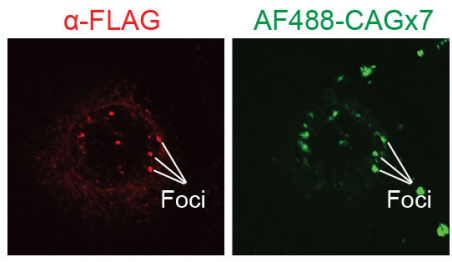

merge

B
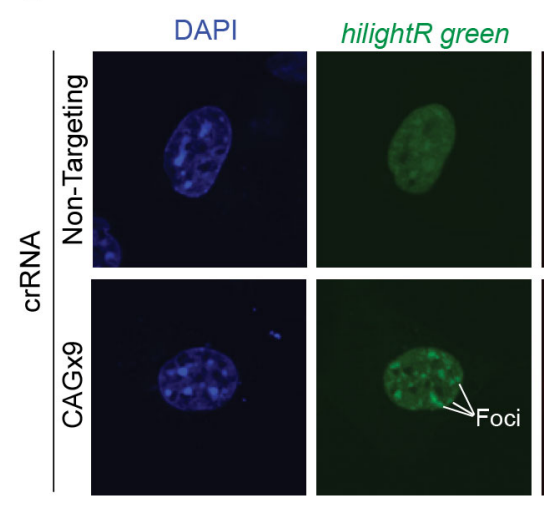

mCherry-

MBNL1
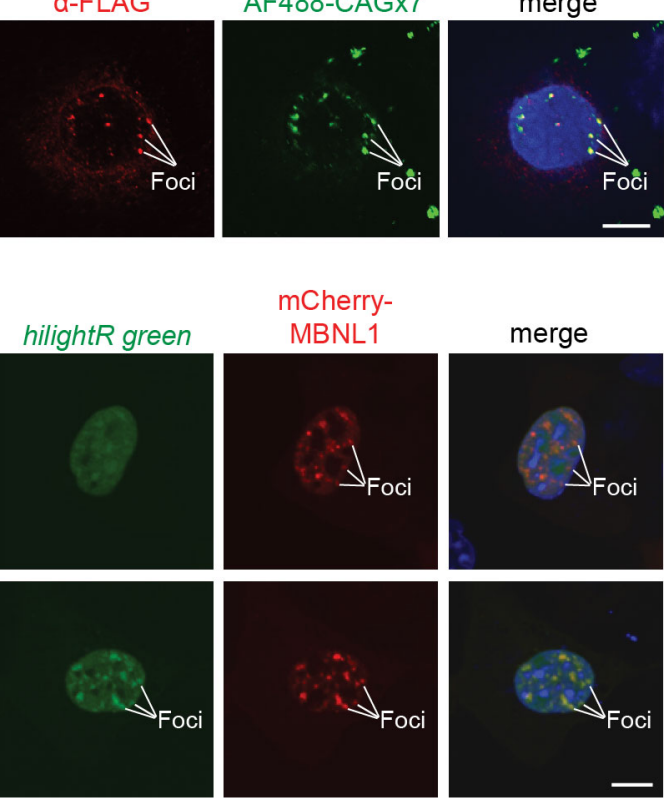

merge
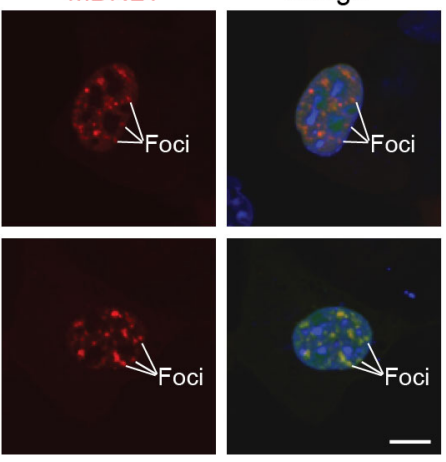

Figure 2 

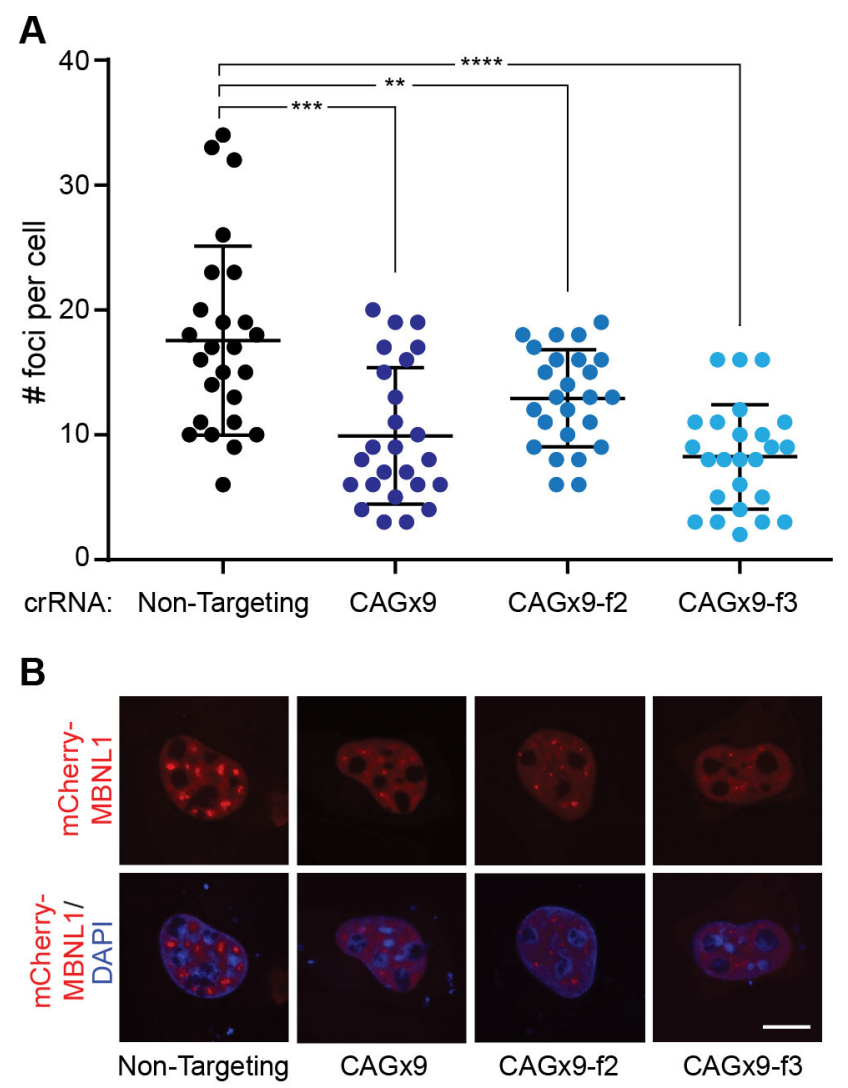

Figure 3 


\section{METHODS}

\section{Synthetic DNA and Cloning}

The mammalian expression vector containing an N-terminal 3x FLAG and Ty1 NLS fused to dPspCas13b (described previously, https://doi.org/10.1101/531111) was modified to encode a C-terminal enhanced Green Fluorescent Protein (eGFP) or red fluorescent protein, mCherry. All crRNAs were designed to be 30 nucleotides in length and start with a $5^{\prime} \mathrm{G}$ for efficient transcription from the hU6 promoter in $\mathrm{pC} 00043^{26}$. The negative control non-targeting crRNA has been previous described ${ }^{26}$. To generate the mCherry-MBNL expression plasmid, the coding sequence of human MBNL1 was designed and synthesized for assembly as a gBlock (IDT, Integrated DNA Technologies) and cloned into the CS2mCherry mammalian expression plasmid $^{32}$. Please see Supplementary Table 1 for cloned sequences. All plasmid insert sequences were verified by Sanger sequencing.

\section{Cell Culture, Transient Transfections and Immunohistochemistry}

The COS7 cell line was maintained in DMEM supplemented with $10 \%$ Fetal Bovine Serum (FBS) with penicillin/streptomycin at $37^{\circ} \mathrm{C}$ in an atmosphere of $5 \% \mathrm{CO}_{2}$. Briefly, 100,000 cells per well we seeded on glass coverslips in 6-well plates and transiently transfected after 24 hours using Fugene6 (Promega) according to manufacturer's protocol. For hilightR experiments, cells were transfected with vectors encoding highlightR, crRNA, mCherry-MBNL1, and DT960 in a ratio of 2:2:2:1, and imaged twentyfour hours post-transfection. For erase R experiments, cells were transfected with vectors 
encoding erase $R$, crRNA, mCherry-MBNL1, and DT960 in a ratio of 2:2:2:1, and imaged forty-eight hours post-transfection. For immunohistochemistry, transiently transfected COS7 cells were fixed in $4 \%$ formaldehyde in DPBS for 15 minutes, blocked in $3 \%$ Bovine Serum Albumin (BSA) and incubated with primary antibodies in 1\% BSA for 4 hours at room temperature. Primary antibodies used were anti-FLAG (Sigma, F1864) at 1:1000 and anti-SC-35 (Abcam, ab11826) at 1:1000. Cells were subsequently incubated with an Alexa Fluor 488 or 594 conjugated secondary antibody (Thermofisher) in 1\% BSA for 30 minutes at room temperature. Coverslips were mounted using anti-fade fluorescent mounting medium containing DAPI (Vector Biolabs, H-1200) and imaged using confocal microscopy.

\section{Fluorescent In Situ Hybridization (FISH)}

Twenty-four hours post-transfection, cells were fixed in ice cold $100 \%$ Methanol for 10 minutes at $-20^{\circ} \mathrm{C}$, then washed 2 times with DPBS and 1 time with Wash Buffer [2X SSC pH 7.0, 10\% Formamide]. Cells were subsequently hybridized with probe in Hybridization Buffer [ 10\% Dextran Sulfate, 2X SSC pH7.0, 10\% Formamide] with a final probe concentration of $100 \mathrm{nM}$. Cells were hybridized overnight at $37^{\circ} \mathrm{C}$. Cells were then washed one time in Wash Buffer at $37^{\circ} \mathrm{C}$ for 30 minutes, then mounted with VectaShield with DAPI (Vector Biolabs) on slides and imaged using confocal microscopy. The probe was a 21-mer DNA oligonucleotide (CAGCAGCAGCAGCAGCAGCAG) conjugated with a 5' Alexa Fluor 488 dye and purified using HPLC (IDT, Integrated DNA Technologies). 


\section{SUPPLEMENTARY DATA}

\section{SUPPLEMENTARY FIGURES}

A
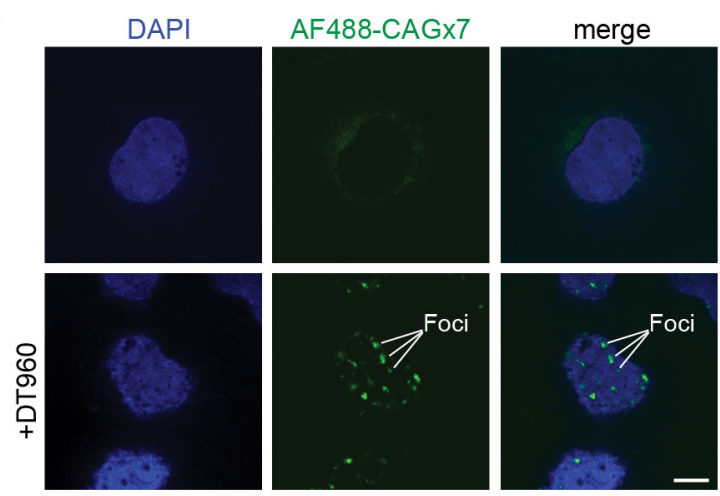

B

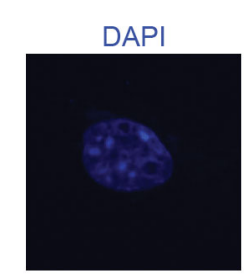

mCherryMBNL1

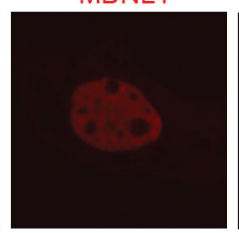

merge
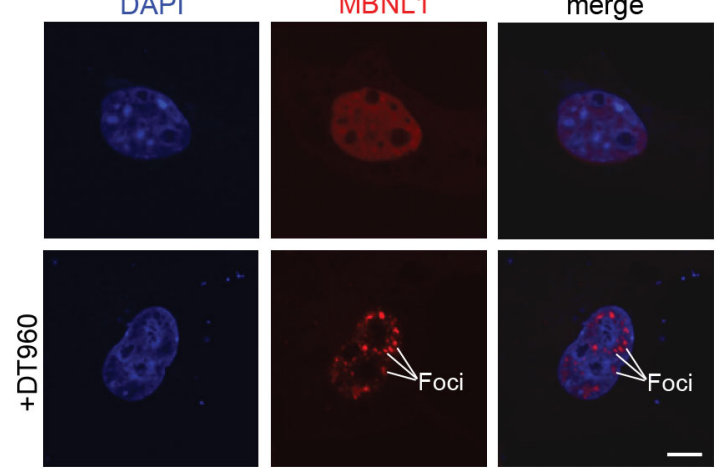

C

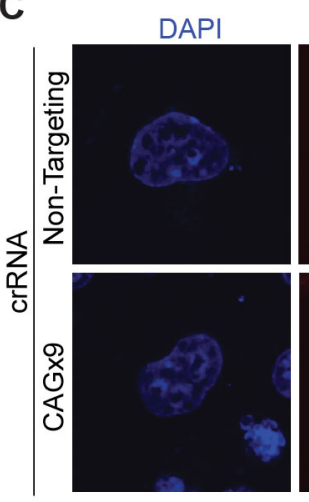

hilightR red
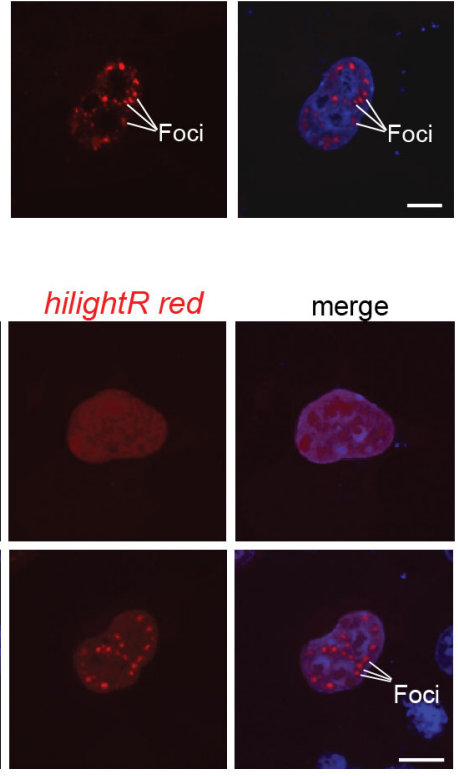

Supplementary Figure 1 Detection of induced CUG ${ }^{\text {exp }}$ RNA foci in COS7 cells. (A) COS7 cells expressing 960 copies of CUG repeats induced RNA foci as detected using FISH with a CAG repeat antisense probe. AF488 - Alexa Fluor 488. (B) Expression of CUG ${ }^{\text {exp }}$ RNA induces the localization of MBNL1 to foci, as detected using an mCherry-MBNL1 
fusion protein. (C) Localization of dPspCas13b-mCherry (hilightR red) guided by either a non-targeting or CAGx9 crRNA in COS7 cells expressing CUG ${ }^{\text {exp }}$ RNA. Scale bars, 10 $\mu \mathrm{m}$.

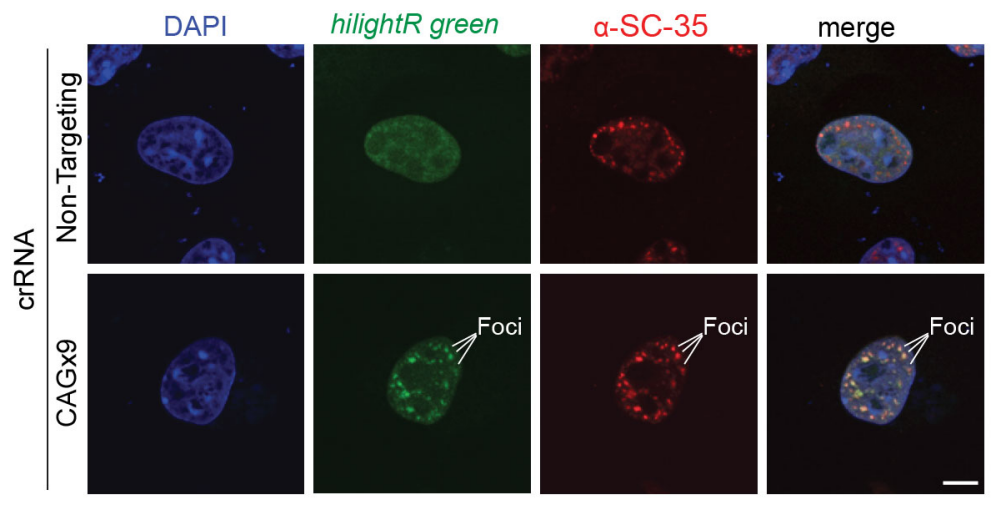

Supplementary Figure 2 Co-localization of hilightR green with splicing speckles. In agreement with previous reports, $\mathrm{CUG}^{\exp }$ RNA foci marked by hilightR green targeted with a CAGx9 crRNA, co-localized with splicing speckles, as detected using an anti-SC35 antibody. Scale bars, $10 \mu \mathrm{m}$. 


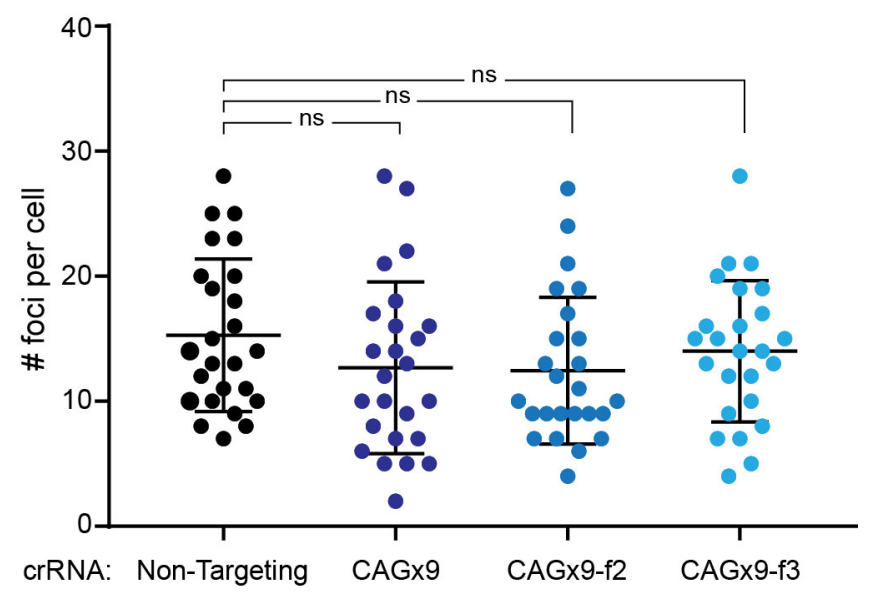

Supplementary Figure 3 Catalytically dead Cas13 (dCas13) does not significantly reduce the number of $C U G^{\text {exp }}$ RNA foci. Expression of dPspCas $13 b$ targeted with $C A G \times 9$ crRNAs does not significantly reduce the number of CUG ${ }^{\exp }$ RNA foci per cell, as detected by mCherry-MBNL1. ns - not significant. 
SUPPLEMENTARY TABLE 1: Sequences

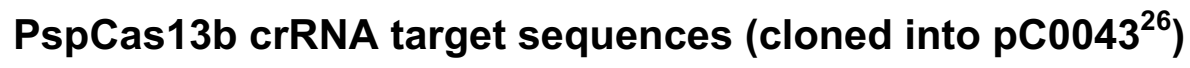

CAGX9

5'-GCAGCAGCAGCAGCAGCAGCAGCAGCAGCA-3'

CAGX9-f2

5'-GAGCAGCAGCAGCAGCAGCAGCAGCAGCAGC-3'

CAGX9-f3

5'-GCAGCAGCAGCAGCAGCAGCAGCAGCAGCAG-3'

\section{QuikChange Site-Directed Mutagenesis primers}

PspCas13b A133H

5'-ATGTACAGGGACCTGACCAACCACTACAAGACCTACGAGGAAAAG-3'

PspCas13b A1058H

5'-AAGATCCGGAACGCCTTCGATCACAACAATTACCCCGACAAAGG-3'

\section{hilightR green}

3xFLAG-Ty1NLS-dPspCas13b-linker-eGFP

ATGGACTACAAAGACCATGACGGTGATTATAAAGATCATGACATCGATTACAAGGATGACGATG ACAAGGGCGGAAACTCAAAGAAAAGGTCACTGGAGGACAACGAAACGGAAATCAAAGTCTCCAG AGACACCTGGAACACTAAGAACATGCGGTCCCTGGAACCGCCACGAAGCAAGAAACGGATACAT GGAGGCAACATCCCCGCTCTGGTGGAAAACCAGAAGAAGTACTTTGGCACCTACAGCGTGATGG CCATGCTGAACGCTCAGACCGTGCTGGACCACATCCAGAAGGTGGCCGATATTGAGGGCGAGCA GAACGAGAACAACGAGAATCTGTGGTTTCACCCCGTGATGAGCCACCTGTACAACGCCAAGAAC GGCTACGACAAGCAGCCCGAGAAAACCATGTTCATCATCGAGCGGCTGCAGAGCTACTTCCCAT TCCTGAAGATCATGGCCGAGAACCAGAGAGAGTACAGCAACGGCAAGTACAAGCAGAACCGCGT GGAAGTGAACAGCAACGACATCTTCGAGGTGCTGAAGCGCGCCTTCGGCGTGCTGAAGATGTAC AGGGACCTGACCAACGCATACAAGACCTACGAGGAAAAGCTGAACGACGGCTGCGAGTTCCTGA CCAGCACAGAGCAACCTCTGAGCGGCATGATCAACAACTACTACACAGTGGCCCTGCGGAACAT GAACGAGAGATACGGCTACAAGACAGAGGACCTGGCCTTCATCCAGGACAAGCGGTTCAAGTTC GTGAAGGACGCCTACGGCAAGAAAAAGTCCCAAGTGAATACCGGATTCTTCCTGAGCCTGCAGG ACTACAACGGCGACACACAGAAGAAGCTGCACCTGAGCGGAGTGGGAATCGCCCTGCTGATCTG CCTGTTCCTGGACAAGCAGTACATCAACATCTTTCTGAGCAGGCTGCCCATCTTCTCCAGCTAC AATGCCCAGAGCGAGGAACGGCGGATCATCATCAGATCCTTCGGCATCAACAGCATCAAGCTGC CCAAGGACCGGATCCACAGCGAGAAGTCCAACAAGAGCGTGGCCATGGATATGCTCAACGAAGT 
GAAGCGGTGCCCCGACGAGCTGTTCACAACACTGTCTGCCGAGAAGCAGTCCCGGTTCAGAATC ATCAGCGACGACCACAATGAAGTGCTGATGAAGCGGAGCAGCGACAGATTCGTGCCTCTGCTGC TGCAGTATATCGATTACGGCAAGCTGTTCGACCACATCAGGTTCCACGTGAACATGGGCAAGCT GAGATACCTGCTGAAGGCCGACAAGACCTGCATCGACGGCCAGACCAGAGTCAGAGTGATCGAG CAGCCCCTGAACGGCTTCGGCAGACTGGAAGAGGCCGAGACAATGCGGAAGCAAGAGAACGGCA CCTTCGGCAACAGCGGCATCCGGATCAGAGACTTCGAGAACATGAAGCGGGACGACGCCAATCC TGCCAACTATCCCTACATCGTGGACACCTACACACACTACATCCTGGAAAACAACAAGGTCGAG ATGTTTATCAACGACAAAGAGGACAGCGCCCCACTGCTGCCCGTGATCGAGGATGATAGATACG TGGTCAAGACAATCCCCAGCTGCCGGATGAGCACCCTGGAAATTCCAGCCATGGCCTTCCACAT GTTTCTGTTCGGCAGCAAGAAAACCGAGAAGCTGATCGTGGACGTGCACAACCGGTACAAGAGA CTGTTCCAGGCCATGCAGAAAGAAGAAGTGACCGCCGAGAATATCGCCAGCTTCGGAATCGCCG AGAGCGACCTGCCTCAGAAGATCCTGGATCTGATCAGCGGCAATGCCCACGGCAAGGATGTGGA CGCCTTCATCAGACTGACCGTGGACGACATGCTGACCGACACCGAGCGGAGAATCAAGAGATTC AAGGACGACCGGAAGTCCATTCGGAGCGCCGACAACAAGATGGGAAAGAGAGGCTTCAAGCAGA TCTCCACAGGCAAGCTGGCCGACTTCCTGGCCAAGGACATCGTGCTGTTTCAGCCCAGCGTGAA CGATGGCGAGAACAAGATCACCGGCCTGAACTACCGGATCATGCAGAGCGCCATTGCCGTGTAC GATAGCGGCGACGATTACGAGGCCAAGCAGCAGTTCAAGCTGATGTTCGAGAAGGCCCGGCTGA TCGGCAAGGGCACAACAGAGCCTCATCCATTTCTGTACAAGGTGTTCGCCCGCAGCATCCCCGC CAATGCCGTCGAGTTCTACGAGCGCTACCTGATCGAGCGGAAGTTCTACCTGACCGGCCTGTCC AACGAGATCAAGAAAGGCAACAGAGTGGATGTGCCCTTCATCCGGCGGGACCAGAACAAGTGGA AAACACCCGCCATGAAGACCCTGGGCAGAATCTACAGCGAGGATCTGCCCGTGGAACTGCCCAG ACAGATGTTCGACAATGAGATCAAGTCCCACCTGAAGTCCCTGCCACAGATGGAAGGCATCGAC TTCAACAATGCCAACGTGACCTATCTGATCGCCGAGTACATGAAGAGAGTGCTGGACGACGACT TCCAGACCTTCTACCAGTGGAACCGCAACTACCGGTACATGGACATGCTTAAGGGCGAGTACGA CAGAAAGGGCTCCCTGCAGCACTGCTTCACCAGCGTGGAAGAGAGAGAAGGCCTCTGGAAAGAG CGGGCCTCCAGAACAGAGCGGTACAGAAAGCAGGCCAGCAACAAGATCCGCAGCAACCGGCAGA TGAGAAACGCCAGCAGCGAAGAGATCGAGACAATCCTGGATAAGCGGCTGAGCAACAGCCGGAA CGAGTACCAGAAAAGCGAGAAAGTGATCCGGCGCTACAGAGTGCAGGATGCCCTGCTGTTTCTG CTGGCCAAAAAGACCCTGACCGAACTGGCCGATTTCGACGGCGAGAGGTTCAAACTGAAAGAAA TCATGCCCGACGCCGAGAAGGGAATCCTGAGCGAGATCATGCCCATGAGCTTCACCTTCGAGAA AGGCGGCAAGAAGTACACCATCACCAGCGAGGGCATGAAGCTGAAGAACTACGGCGACTTCTTT GTGCTGGCTAGCGACAAGAGGATCGGCAACCTGCTGGAACTCGTGGGCAGCGACATCGTGTCCA AAGAGGATATCATGGAAGAGTTCAACAAATACGACCAGTGCAGGCCCGAGATCAGCTCCATCGT GTTCAACCTGGAAAAGTGGGCCTTCGACACATACCCCGAGCTGTCTGCCAGAGTGGACCGGGAA GAGAAGGTGGACTTCAAGAGCATCCTGAAAATCCTGCTGAACAACAAGAACATCAACAAAGAGC AGAGCGACATCCTGCGGAAGATCCGGAACGCCTTCGATGCAAACAATTACCCCGACAAAGGCGT GGTGGAAATCAAGGCCCTGCCTGAGATCGCCATGAGCATCAAGAAGGCCTTTGGGGAGTACGCC ATCATGAAGTCGCGAGGCGGTGGAGGTAGTGGAGGGGGAGGATCAACGCGTGTGAGCAAGGGCG AGGAGCTGTTCACCGGGGTGGTGCCCATCCTGGTCGAGCTGGACGGCGACGTAAACGGCCACAA GTTCAGCGTGTCCGGCGAGGGCGAGGGCGATGCCACCTACGGCAAGCTGACCCTGAAGTTCATC TGCACCACCGGCAAGCTGCCCGTGCCCTGGCCCACCCTCGTGACCACCCTGACCTACGGCGTGC AGTGCTTCAGCCGCTACCCCGACCACATGAAGCAGCACGACTTCTTCAAGTCCGCCATGCCCGA AGGCTACGTCCAGGAGCGCACCATCTTCTTCAAGGACGACGGCAACTACAAGACCCGCGCCGAG GTGAAGTTCGAGGGCGACACCCTGGTGAACCGCATCGAGCTGAAGGGCATCGACTTCAAGGAGG ACGGCAACATCCTGGGGCACAAGCTGGAGTACAACTACAACAGCCACAACGTCTATATCATGGC CGACAAGCAGAAGAACGGCATCAAGGTGAACTTCAAGATCCGCCACAACATCGAGGACGGCAGC 
GTGCAGCTCGCCGACCACTACCAGCAGAACACCCCCATCGGCGACGGCCCCGTGCTGCTGCCCG ACAACCACTACCTGAGCACCCAGTCCGCCCTGAGCAAAGACCCCAACGAGAAGCGCGATCACAT GGTCCTGCTGGAGTTCGTGACCGCCGCCGGGATCACTCTCGGCATGGACGAGCTGTACAAGTAG TAA

3xFLAG-Ty1NLS-dPspCas13b-linker-eGFP

MDYKDHDGDYKDHDIDYKDDDDKGGNSKKRSLEDNETEIKVSRDTWNTKNMRSLEPPRSKKRIH GGNIPALVENQKKYFGTYSVMAMLNAQTVLDHIQKVADIEGEQNENNENLWFHPVMSHLYNAKN GYDKQPEKTMFIIERLQSYFPFLKIMAENQREYSNGKYKQNRVEVNSNDIFEVLKRAFGVLKMY RDLTNAYKTYEEKLNDGCEFLTSTEQPLSGMINNYYTVALRNMNERYGYKTEDLAFIQDKRFKF VKDAYGKKKSQVNTGFFLSLQDYNGDTQKKLHLSGVGIALLICLFLDKQYINIFLSRLPIFSSY NAQSEERRIIIRSFGINSIKLPKDRIHSEKSNKSVAMDMLNEVKRCPDELFTTLSAEKQSRFRI ISDDHNEVLMKRSSDRFVPLLLQYIDYGKLFDHIRFHVNMGKLRYLLKADKTCIDGQTRVRVIE QPLNGFGRLEEAETMRKQENGTFGNSGIRIRDFENMKRDDANPANYPYIVDTYTHYILENNKVE MFINDKEDSAPLLPVIEDDRYVVKTIPSCRMSTLEIPAMAFHMFLFGSKKTEKLIVDVHNRYKR LFQAMQKEEVTAENIASFGIAESDLPQKILDLISGNAHGKDVDAFIRLTVDDMLTDTERRIKRF KDDRKSIRSADNKMGKRGFKQISTGKLADFLAKDIVLFQPSVNDGENKITGLNYRIMQSAIAVY DSGDDYEAKQQFKLMFEKARLIGKGTTEPHPFLYKVFARSIPANAVEFYERYLIERKFYLTGLS NEIKKGNRVDVPFIRRDQNKWKTPAMKTLGRIYSEDLPVELPRQMFDNEIKSHLKSLPQMEGID FNNANVTYLIAEYMKRVLDDDFQTFYQWNRNYRYMDMLKGEYDRKGSLQHCFTSVEEREGLWKE RASRTERYRKQASNKIRSNRQMRNASSEEIETILDKRLSNSRNEYQKSEKVIRRYRVQDALLFL LAKKTLTELADFDGERFKLKEIMPDAEKGILSEIMPMSFTFEKGGKKYTITSEGMKLKNYGDFF VLASDKRIGNLLELVGSDIVSKEDIMEEFNKYDQCRPEISSIVFNLEKWAFDTYPELSARVDRE EKVDFKSILKILLNNKNINKEQSDILRKIRNAFDANNYPDKGVVEIKALPEIAMSIKKAFGEYA IMKSRGGGGSGGGGSTRVSKGEELFTGVVPILVELDGDVNGHKFSVSGEGEGDATYGKLTLKFI CTTGKLPVPWPTLVTTLTYGVQCFSRYPDHMKQHDFFKSAMPEGYVQERTIFFKDDGNYKTRAE VKFEGDTLVNRIELKGIDFKEDGNILGHKLEYNYNSHNVYIMADKQKNGIKVNFKIRHNIEDGS VQLADHYQQNTPIGDGPVLLPDNHYLSTQSALSKDPNEKRDHMVLLEFVTAAGITLGMDELYK* *

\section{hilightR red}

3xFLAG-Ty1NLS-dPspCas13b-linker-mCherry

ATGGACTACAAAGACCATGACGGTGATTATAAAGATCATGACATCGATTACAAGGATGACGATG ACAAGGGCGGAAACTCAAAGAAAAGGTCACTGGAGGACAACGAAACGGAAATCAAAGTCTCCAG AGACACCTGGAACACTAAGAACATGCGGTCCCTGGAACCGCCACGAAGCAAGAAACGGATACAT GGAGGCAACATCCCCGCTCTGGTGGAAAACCAGAAGAAGTACTTTGGCACCTACAGCGTGATGG CCATGCTGAACGCTCAGACCGTGCTGGACCACATCCAGAAGGTGGCCGATATTGAGGGCGAGCA GAACGAGAACAACGAGAATCTGTGGTTTCACCCCGTGATGAGCCACCTGTACAACGCCAAGAAC GGCTACGACAAGCAGCCCGAGAAAACCATGTTCATCATCGAGCGGCTGCAGAGCTACTTCCCAT TCCTGAAGATCATGGCCGAGAACCAGAGAGAGTACAGCAACGGCAAGTACAAGCAGAACCGCGT GGAAGTGAACAGCAACGACATCTTCGAGGTGCTGAAGCGCGCCTTCGGCGTGCTGAAGATGTAC AGGGACCTGACCAACGCATACAAGACCTACGAGGAAAAGCTGAACGACGGCTGCGAGTTCCTGA CCAGCACAGAGCAACCTCTGAGCGGCATGATCAACAACTACTACACAGTGGCCCTGCGGAACAT GAACGAGAGATACGGCTACAAGACAGAGGACCTGGCCTTCATCCAGGACAAGCGGTTCAAGTTC 
GTGAAGGACGCCTACGGCAAGAAAAAGTCCCAAGTGAATACCGGATTCTTCCTGAGCCTGCAGG ACTACAACGGCGACACACAGAAGAAGCTGCACCTGAGCGGAGTGGGAATCGCCCTGCTGATCTG CCTGTTCCTGGACAAGCAGTACATCAACATCTTTCTGAGCAGGCTGCCCATCTTCTCCAGCTAC AATGCCCAGAGCGAGGAACGGCGGATCATCATCAGATCCTTCGGCATCAACAGCATCAAGCTGC CCAAGGACCGGATCCACAGCGAGAAGTCCAACAAGAGCGTGGCCATGGATATGCTCAACGAAGT GAAGCGGTGCCCCGACGAGCTGTTCACAACACTGTCTGCCGAGAAGCAGTCCCGGTTCAGAATC ATCAGCGACGACCACAATGAAGTGCTGATGAAGCGGAGCAGCGACAGATTCGTGCCTCTGCTGC TGCAGTATATCGATTACGGCAAGCTGTTCGACCACATCAGGTTCCACGTGAACATGGGCAAGCT GAGATACCTGCTGAAGGCCGACAAGACCTGCATCGACGGCCAGACCAGAGTCAGAGTGATCGAG CAGCCCCTGAACGGCTTCGGCAGACTGGAAGAGGCCGAGACAATGCGGAAGCAAGAGAACGGCA CCTTCGGCAACAGCGGCATCCGGATCAGAGACTTCGAGAACATGAAGCGGGACGACGCCAATCC TGCCAACTATCCCTACATCGTGGACACCTACACACACTACATCCTGGAAAACAACAAGGTCGAG ATGTTTATCAACGACAAAGAGGACAGCGCCCCACTGCTGCCCGTGATCGAGGATGATAGATACG TGGTCAAGACAATCCCCAGCTGCCGGATGAGCACCCTGGAAATTCCAGCCATGGCCTTCCACAT GTTTCTGTTCGGCAGCAAGAAAACCGAGAAGCTGATCGTGGACGTGCACAACCGGTACAAGAGA CTGTTCCAGGCCATGCAGAAAGAAGAAGTGACCGCCGAGAATATCGCCAGCTTCGGAATCGCCG AGAGCGACCTGCCTCAGAAGATCCTGGATCTGATCAGCGGCAATGCCCACGGCAAGGATGTGGA CGCCTTCATCAGACTGACCGTGGACGACATGCTGACCGACACCGAGCGGAGAATCAAGAGATTC AAGGACGACCGGAAGTCCATTCGGAGCGCCGACAACAAGATGGGAAAGAGAGGCTTCAAGCAGA TCTCCACAGGCAAGCTGGCCGACTTCCTGGCCAAGGACATCGTGCTGTTTCAGCCCAGCGTGAA CGATGGCGAGAACAAGATCACCGGCCTGAACTACCGGATCATGCAGAGCGCCATTGCCGTGTAC GATAGCGGCGACGATTACGAGGCCAAGCAGCAGTTCAAGCTGATGTTCGAGAAGGCCCGGCTGA TCGGCAAGGGCACAACAGAGCCTCATCCATTTCTGTACAAGGTGTTCGCCCGCAGCATCCCCGC CAATGCCGTCGAGTTCTACGAGCGCTACCTGATCGAGCGGAAGTTCTACCTGACCGGCCTGTCC AACGAGATCAAGAAAGGCAACAGAGTGGATGTGCCCTTCATCCGGCGGGACCAGAACAAGTGGA AAACACCCGCCATGAAGACCCTGGGCAGAATCTACAGCGAGGATCTGCCCGTGGAACTGCCCAG ACAGATGTTCGACAATGAGATCAAGTCCCACCTGAAGTCCCTGCCACAGATGGAAGGCATCGAC TTCAACAATGCCAACGTGACCTATCTGATCGCCGAGTACATGAAGAGAGTGCTGGACGACGACT TCCAGACCTTCTACCAGTGGAACCGCAACTACCGGTACATGGACATGCTTAAGGGCGAGTACGA CAGAAAGGGCTCCCTGCAGCACTGCTTCACCAGCGTGGAAGAGAGAGAAGGCCTCTGGAAAGAG CGGGCCTCCAGAACAGAGCGGTACAGAAAGCAGGCCAGCAACAAGATCCGCAGCAACCGGCAGA TGAGAAACGCCAGCAGCGAAGAGATCGAGACAATCCTGGATAAGCGGCTGAGCAACAGCCGGAA CGAGTACCAGAAAAGCGAGAAAGTGATCCGGCGCTACAGAGTGCAGGATGCCCTGCTGTTTCTG CTGGCCAAAAAGACCCTGACCGAACTGGCCGATTTCGACGGCGAGAGGTTCAAACTGAAAGAAA TCATGCCCGACGCCGAGAAGGGAATCCTGAGCGAGATCATGCCCATGAGCTTCACCTTCGAGAA AGGCGGCAAGAAGTACACCATCACCAGCGAGGGCATGAAGCTGAAGAACTACGGCGACTTCTTT GTGCTGGCTAGCGACAAGAGGATCGGCAACCTGCTGGAACTCGTGGGCAGCGACATCGTGTCCA AAGAGGATATCATGGAAGAGTTCAACAAATACGACCAGTGCAGGCCCGAGATCAGCTCCATCGT GTTCAACCTGGAAAAGTGGGCCTTCGACACATACCCCGAGCTGTCTGCCAGAGTGGACCGGGAA GAGAAGGTGGACTTCAAGAGCATCCTGAAAATCCTGCTGAACAACAAGAACATCAACAAAGAGC AGAGCGACATCCTGCGGAAGATCCGGAACGCCTTCGATGCAAACAATTACCCCGACAAAGGCGT GGTGGAAATCAAGGCCCTGCCTGAGATCGCCATGAGCATCAAGAAGGCCTTTGGGGAGTACGCC ATCATGAAGTCGCGAGGCGGTGGAGGTAGTGGAGGGGGAGGATCAACGCGTGTGAGCAAGGGCG AGGAGGATAACATGGCCATCATCAAGGAGTTCATGCGCTTCAAGGTGCACATGGAGGGCTCCGT GAACGGCCACGAGTTCGAGATCGAGGGCGAGGGCGAGGGCCGCCCCTACGAGGGCACCCAGACC GCCAAGCTGAAGGTGACCAAGGGTGGCCCCCTGCCCTTCGCCTGGGACATCCTGTCCCCTCAGT 
TCATGTACGGCTCCAAGGCCTACGTGAAGCACCCCGCCGACATCCCCGACTACTTGAAGCTGTC CTTCCCCGAGGGCTTCAAGTGGGAGCGCGTGATGAACTTCGAGGACGGCGGCGTGGTGACCGTG ACCCAGGACTCCTCCCTGCAGGACGGCGAGTTCATCTACAAGGTGAAGCTGCGCGGCACCAACT TCCCCTCCGACGGCCCCGTAATGCAGAAGAAGACCATGGGCTGGGAGGCCTCCTCCGAGCGGAT GTACCCCGAGGACGGCGCCCTGAAGGGCGAGATCAAGCAGAGGCTGAAGCTGAAGGACGGCGGC CACTACGACGCTGAGGTCAAGACCACCTACAAGGCCAAGAAGCCCGTGCAGCTGCCCGGCGCCT ACAACGTCAACATCAAGTTGGACATCACCTCCCACAACGAGGACTACACCATCGTGGAACAGTA CGAACGCGCCGAGGGCCGCCACTCCACCGGCGGCATGGACGAGCTGTACAAGTAGTAA

3xFLAG-Ty1NLS-dPspCas13b-linker-eGFP

MDYKDHDGDYKDHDIDYKDDDDKGGNSKKRSLEDNETEIKVSRDTWNTKNMRSLEPPRSKKRIH GGNIPALVENQKKYFGTYSVMAMLNAQTVLDHIQKVADIEGEQNENNENLWFHPVMSHLYNAKN GYDKQPEKTMFIIERLQSYFPFLKIMAENQREYSNGKYKQNRVEVNSNDIFEVLKRAFGVLKMY RDLTNAYKTYEEKLNDGCEFLTSTEQPLSGMINNYYTVALRNMNERYGYKTEDLAFIQDKRFKF VKDAYGKKKSQVNTGFFLSLQDYNGDTQKKLHLSGVGIALLICLFLDKQYINIFLSRLPIFSSY NAQSEERRIIIRSFGINSIKLPKDRIHSEKSNKSVAMDMLNEVKRCPDELFTTLSAEKQSRFRI ISDDHNEVLMKRSSDRFVPLLLQYIDYGKLFDHIRFHVNMGKLRYLLKADKTCIDGQTRVRVIE QPLNGFGRLEEAETMRKQENGTFGNSGIRIRDFENMKRDDANPANYPYIVDTYTHYILENNKVE MFINDKEDSAPLLPVIEDDRYVVKTIPSCRMSTLEIPAMAFHMFLFGSKKTEKLIVDVHNRYKR LFQAMQKEEVTAENIASFGIAESDLPQKILDLISGNAHGKDVDAFIRLTVDDMLTDTERRIKRF KDDRKSIRSADNKMGKRGFKQISTGKLADFLAKDIVLFQPSVNDGENKITGLNYRIMQSAIAVY DSGDDYEAKQQFKLMFEKARLIGKGTTEPHPFLYKVFARSIPANAVEFYERYLIERKFYLTGLS NEIKKGNRVDVPFIRRDQNKWKTPAMKTLGRIYSEDLPVELPRQMFDNEIKSHLKSLPQMEGID FNNANVTYLIAEYMKRVLDDDFQTFYQWNRNYRYMDMLKGEYDRKGSLQHCFTSVEEREGLWKE RASRTERYRKQASNKIRSNRQMRNASSEEIETILDKRLSNSRNEYQKSEKVIRRYRVQDALLFL LAKKTLTELADFDGERFKLKEIMPDAEKGILSEIMPMSFTFEKGGKKYTITSEGMKLKNYGDFF VLASDKRIGNLLELVGSDIVSKEDIMEEFNKYDQCRPEISSIVFNLEKWAFDTYPELSARVDRE EKVDFKSILKILLNNKNINKEQSDILRKIRNAFDANNYPDKGVVEIKALPEIAMSIKKAFGEYA IMKSRGGGGSGGGGSTRVSKGEEDNMAIIKEFMRFKVHMEGSVNGHEFEIEGEGEGRPYEGTQT AKLKVTKGGPLPFAWDILSPQFMYGSKAYVKHPADIPDYLKLSFPEGFKWERVMNFEDGGVVTV TQDSSLQDGEFIYKVKLRGTNFPSDGPVMQKKTMGWEASSERMYPEDGALKGEIKQRLKLKDGG HYDAEVKTTYKAKKPVQLPGAYNVNIKLDITSHNEDYTIVEQYERAEGRHSTGGMDELYK**

\section{CS2-mCherry-MBNL1}

mCherry-MBNL1

ATGGTGAGCAAGGGCGAGGAGGATAACATGGCCATCATCAAGGAGTTCATGCGCTTCAAGGTGC ACATGGAGGGCTCCGTGAACGGCCACGAGTTCGAGATCGAGGGCGAGGGCGAGGGCCGCCCCTA CGAGGGCACCCAGACCGCCAAGCTGAAGGTGACCAAGGGTGGCCCCCTGCCCTTCGCCTGGGAC ATCCTGTCCCCTCAGTTCATGTACGGCTCCAAGGCCTACGTGAAGCACCCCGCCGACATCCCCG ACTACTTGAAGCTGTCCTTCCCCGAGGGCTTCAAGTGGGAGCGCGTGATGAACTTCGAGGACGG CGGCGTGGTGACCGTGACCCAGGACTCCTCCCTGCAGGACGGCGAGTTCATCTACAAGGTGAAG CTGCGCGGCACCAACTTCCCCTCCGACGGCCCCGTAATGCAGAAGAAGACCATGGGCTGGGAGG 
CCTCCTCCGAGCGGATGTACCCCGAGGACGGCGCCCTGAAGGGCGAGATCAAGCAGAGGCTGAA GCTGAAGGACGGCGGCCACTACGACGCTGAGGTCAAGACCACCTACAAGGCCAAGAAGCCCGTG CAGCTGCCCGGCGCCTACAACGTCAACATCAAGTTGGACATCACCTCCCACAACGAGGACTACA CCATCGTGGAACAGTACGAACGCGCCGAGGGCCGCCACTCCACCGGCGGCATGGACGAGCTGTA CAAGGGGAATTCAAGGCCTCTCGAGGCAGTCTCTGTAACACCAATTAGGGATACCAAATGGCTG ACGCTGGAGGTATGCCGAGAGTTTCAACGCGGAACCTGTAGTCGCCCTGATACGGAGTGCAAGT TTGCCCACCCCTCTAAGTCTTGCCAAGTAGAGAATGGGAGAGTCATCGCTTGCTTCGACAGTCT TAAAGGCCGATGTTCACGGGAAAACTGCAAATATCTTCACCCGCCGCCACATCTCAAAACTCAG CTTGAGATCAACGGTCGGAACAACCTTATCCAACAGAAAAATATGGCTATGTTGGCGCAGCAGA TGCAGCTTGCAAATGCTATGATGCCCGGTGCACCTTTGCAACCGGTTCCAATGTTCTCAGTGGC TCCATCCCTCGCAACAAATGCCTCCGCAGCGGCTTTTAACCCGTACCTCGGCCCCGTATCCCCA TCCCTTGTGCCCGCGGAGATACTTCCGACGGCACCCATGTTGGTTACAGGCAATCCAGGGGTAC CCGTACCCGCGGCAGCGGCCGCTGCGGCGCAAAAACTTATGCGGACAGATCGGCTCGAAGTCTG TAGAGAATATCAAAGGGGTAACTGTAACAGGGGGGAAAACGACTGCAGATTCGCTCACCCAGCG GATAGTACAATGATCGACACGAATGACAACACCGTTACCGTATGCATGGACTACATTAAGGGCC GCTGCAGCAGAGAGAAGTGCAAATACTTTCACCCACCCGCCCATCTGCAAGCCAAAATCAAGGC GGCTCAATACCAAGTCAATCAAGCGGCGGCCGCTCAAGCCGCAGCCACTGCGGCAGCAATGGGT ATCCCGCAAGCCGTTCTTCCCCCTCTCCCAAAGCGACCGGCCCTCGAAAAAACCAATGGAGCTA CCGCCGTCTTCAATACGGGCATCTTCCAGTACCAACAAGCCTTGGCTAATATGCAACTTCAACA ACACACAGCGTTCTTGCCACCAGGATCTATCCTTTGCATGACGCCAGCCACGAGTGTGGTGCCC ATGGTTCACGGTGCGACGCCAGCGACTGTATCTGCGGCTACTACGTCCGCAACATCCGTTCCGT TTGCCGCGACTGCCACGGCAAATCAAATACCGATAATTAGCGCAGAACACTTGACGAGCCACAA ATACGTCACTCAAATGTAG

mCherry-MBNL1

MVSKGEEDNMAI IKEFMRFKVHMEGSVNGHEFEIEGEGEGRPYEGTQTAKLKVTKGGPLPFAWD ILSPQFMYGSKAYVKHPADIPDYLKLSFPEGFKWERVMNFEDGGVVTVTQDSSLQDGEFIYKVK LRGTNFPSDGPVMQKKTMGWEASSERMYPEDGALKGEIKQRLKLKDGGHYDAEVKTTYKAKKPV QLPGAYNVNIKLDITSHNEDYTIVEQYERAEGRHSTGGMDELYKGNSRPLEAVSVTPIRDTKWL TLEVCREFQRGTCSRPDTECKFAHPSKSCQVENGRVIACFDSLKGRCSRENCKYLHPPPHLKTQ LEINGRNNLIQQKNMAMLAQQMQLANAMMPGAPLQPVPMFSVAPSLATNASAAAFNPYLGPVSP SLVPAEILPTAPMLVTGNPGVPVPAAAAAAAQKLMRTDRLEVCREYQRGNCNRGENDCRFAHPA DSTMIDTNDNTVTVCMDYIKGRCSREKCKYFHPPAHLQAKIKAAQYQVNQAAAAQAAATAAAMG IPQAVLPPLPKRPALEKTNGATAVFNTGIFQYQQALANMQLQQHTAFLPPGSILCMTPATSVVP MVHGATPATVSAATTSATSVPFAATATANQIPIISAEHLTSHKYVTQM*

\section{erase $R$}

3xFLAG-Ty1NLS-PspCas13b

ATGGACTACAAAGACCATGACGGTGATTATAAAGATCATGACATCGATTACAAGGATGACGATG ACAAGGGCGGAAACTCAAAGAAAAGGTCACTGGAGGACAACGAAACGGAAATCAAAGTCTCCAG AGACACCTGGAACACTAAGAACATGCGGTCCCTGGAACCGCCACGAAGCAAGAAACGGATACAT GGAGGCAACATCCCCGCTCTGGTGGAAAACCAGAAGAAGTACTTTGGCACCTACAGCGTGATGG CCATGCTGAACGCTCAGACCGTGCTGGACCACATCCAGAAGGTGGCCGATATTGAGGGCGAGCA GAACGAGAACAACGAGAATCTGTGGTTTCACCCCGTGATGAGCCACCTGTACAACGCCAAGAAC 
GGCTACGACAAGCAGCCCGAGAAAACCATGTTCATCATCGAGCGGCTGCAGAGCTACTTCCCAT TCCTGAAGATCATGGCCGAGAACCAGAGAGAGTACAGCAACGGCAAGTACAAGCAGAACCGCGT GGAAGTGAACAGCAACGACATCTTCGAGGTGCTGAAGCGCGCCTTCGGCGTGCTGAAGATGTAC AGGGACCTGACCAACCACTACAAGACCTACGAGGAAAAGCTGAACGACGGCTGCGAGTTCCTGA CCAGCACAGAGCAACCTCTGAGCGGCATGATCAACAACTACTACACAGTGGCCCTGCGGAACAT GAACGAGAGATACGGCTACAAGACAGAGGACCTGGCCTTCATCCAGGACAAGCGGTTCAAGTTC GTGAAGGACGCCTACGGCAAGAAAAAGTCCCAAGTGAATACCGGATTCTTCCTGAGCCTGCAGG ACTACAACGGCGACACACAGAAGAAGCTGCACCTGAGCGGAGTGGGAATCGCCCTGCTGATCTG CCTGTTCCTGGACAAGCAGTACATCAACATCTTTCTGAGCAGGCTGCCCATCTTCTCCAGCTAC AATGCCCAGAGCGAGGAACGGCGGATCATCATCAGATCCTTCGGCATCAACAGCATCAAGCTGC CCAAGGACCGGATCCACAGCGAGAAGTCCAACAAGAGCGTGGCCATGGATATGCTCAACGAAGT GAAGCGGTGCCCCGACGAGCTGTTCACAACACTGTCTGCCGAGAAGCAGTCCCGGTTCAGAATC ATCAGCGACGACCACAATGAAGTGCTGATGAAGCGGAGCAGCGACAGATTCGTGCCTCTGCTGC TGCAGTATATCGATTACGGCAAGCTGTTCGACCACATCAGGTTCCACGTGAACATGGGCAAGCT GAGATACCTGCTGAAGGCCGACAAGACCTGCATCGACGGCCAGACCAGAGTCAGAGTGATCGAG CAGCCCCTGAACGGCTTCGGCAGACTGGAAGAGGCCGAGACAATGCGGAAGCAAGAGAACGGCA CCTTCGGCAACAGCGGCATCCGGATCAGAGACTTCGAGAACATGAAGCGGGACGACGCCAATCC TGCCAACTATCCCTACATCGTGGACACCTACACACACTACATCCTGGAAAACAACAAGGTCGAG ATGTTTATCAACGACAAAGAGGACAGCGCCCCACTGCTGCCCGTGATCGAGGATGATAGATACG TGGTCAAGACAATCCCCAGCTGCCGGATGAGCACCCTGGAAATTCCAGCCATGGCCTTCCACAT GTTTCTGTTCGGCAGCAAGAAAACCGAGAAGCTGATCGTGGACGTGCACAACCGGTACAAGAGA CTGTTCCAGGCCATGCAGAAAGAAGAAGTGACCGCCGAGAATATCGCCAGCTTCGGAATCGCCG AGAGCGACCTGCCTCAGAAGATCCTGGATCTGATCAGCGGCAATGCCCACGGCAAGGATGTGGA CGCCTTCATCAGACTGACCGTGGACGACATGCTGACCGACACCGAGCGGAGAATCAAGAGATTC AAGGACGACCGGAAGTCCATTCGGAGCGCCGACAACAAGATGGGAAAGAGAGGCTTCAAGCAGA TCTCCACAGGCAAGCTGGCCGACTTCCTGGCCAAGGACATCGTGCTGTTTCAGCCCAGCGTGAA CGATGGCGAGAACAAGATCACCGGCCTGAACTACCGGATCATGCAGAGCGCCATTGCCGTGTAC GATAGCGGCGACGATTACGAGGCCAAGCAGCAGTTCAAGCTGATGTTCGAGAAGGCCCGGCTGA TCGGCAAGGGCACAACAGAGCCTCATCCATTTCTGTACAAGGTGTTCGCCCGCAGCATCCCCGC CAATGCCGTCGAGTTCTACGAGCGCTACCTGATCGAGCGGAAGTTCTACCTGACCGGCCTGTCC AACGAGATCAAGAAAGGCAACAGAGTGGATGTGCCCTTCATCCGGCGGGACCAGAACAAGTGGA AAACACCCGCCATGAAGACCCTGGGCAGAATCTACAGCGAGGATCTGCCCGTGGAACTGCCCAG ACAGATGTTCGACAATGAGATCAAGTCCCACCTGAAGTCCCTGCCACAGATGGAAGGCATCGAC TTCAACAATGCCAACGTGACCTATCTGATCGCCGAGTACATGAAGAGAGTGCTGGACGACGACT TCCAGACCTTCTACCAGTGGAACCGCAACTACCGGTACATGGACATGCTTAAGGGCGAGTACGA CAGAAAGGGCTCCCTGCAGCACTGCTTCACCAGCGTGGAAGAGAGAGAAGGCCTCTGGAAAGAG CGGGCCTCCAGAACAGAGCGGTACAGAAAGCAGGCCAGCAACAAGATCCGCAGCAACCGGCAGA TGAGAAACGCCAGCAGCGAAGAGATCGAGACAATCCTGGATAAGCGGCTGAGCAACAGCCGGAA CGAGTACCAGAAAAGCGAGAAAGTGATCCGGCGCTACAGAGTGCAGGATGCCCTGCTGTTTCTG CTGGCCAAAAAGACCCTGACCGAACTGGCCGATTTCGACGGCGAGAGGTTCAAACTGAAAGAAA TCATGCCCGACGCCGAGAAGGGAATCCTGAGCGAGATCATGCCCATGAGCTTCACCTTCGAGAA AGGCGGCAAGAAGTACACCATCACCAGCGAGGGCATGAAGCTGAAGAACTACGGCGACTTCTTT GTGCTGGCTAGCGACAAGAGGATCGGCAACCTGCTGGAACTCGTGGGCAGCGACATCGTGTCCA AAGAGGATATCATGGAAGAGTTCAACAAATACGACCAGTGCAGGCCCGAGATCAGCTCCATCGT GTTCAACCTGGAAAAGTGGGCCTTCGACACATACCCCGAGCTGTCTGCCAGAGTGGACCGGGAA GAGAAGGTGGACTTCAAGAGCATCCTGAAAATCCTGCTGAACAACAAGAACATCAACAAAGAGC 

GGTGGAAATCAAGGCCCTGCCTGAGATCGCCATGAGCATCAAGAAGGCCTTTGGGGAGTACGCC ATCATGAAGTAGTAA

3xFLAG-Ty1NLS-PspCas13b

MDYKDHDGDYKDHDIDYKDDDDKGGNSKKRSLEDNETEIKVSRDTWNTKNMRSLEPPRSKKRIH GGNIPALVENQKKYFGTYSVMAMLNAQTVLDHIQKVADIEGEQNENNENLWFHPVMSHLYNAKN GYDKQPEKTMFI IERLQSYFPFLKIMAENQREYSNGKYKQNRVEVNSNDIFEVLKRAFGVLKMY RDLTNHYKTYEEKLNDGCEFLTSTEQPLSGMINNYYTVALRNMNERYGYKTEDLAFIQDKRFKF VKDAYGKKKSQVNTGFFLSLQDYNGDTQKKLHLSGVGIALLICLFLDKQYINIFLSRLPIFSSY NAQSEERRIIIRSFGINSIKLPKDRIHSEKSNKSVAMDMLNEVKRCPDELFTTLSAEKQSRFRI ISDDHNEVLMKRSSDRFVPLLLQYIDYGKLFDHIRFHVNMGKLRYLLKADKTCIDGQTRVRVIE QPLNGFGRLEEAETMRKQENGTFGNSGIRIRDFENMKRDDANPANYPYIVDTYTHYILENNKVE MFINDKEDSAPLLPVIEDDRYVVKTIPSCRMSTLEIPAMAFHMFLFGSKKTEKLIVDVHNRYKR LFQAMQKEEVTAENIASFGIAESDLPQKILDLISGNAHGKDVDAFIRLTVDDMLTDTERRIKRF KDDRKSIRSADNKMGKRGFKQISTGKLADFLAKDIVLFQPSVNDGENKITGLNYRIMQSAIAVY DSGDDYEAKQQFKLMFEKARLIGKGTTEPHPFLYKVFARSIPANAVEFYERYLIERKFYLTGLS NEIKKGNRVDVPFIRRDQNKWKTPAMKTLGRIYSEDLPVELPRQMFDNEIKSHLKSLPQMEGID FNNANVTYLIAEYMKRVLDDDFQTFYQWNRNYRYMDMLKGEYDRKGSLQHCFTSVEEREGLWKE RASRTERYRKQASNKIRSNRQMRNASSEEIETILDKRLSNSRNEYQKSEKVIRRYRVQDALLFL LAKKTLTELADFDGERFKLKEIMPDAEKGILSEIMPMSFTFEKGGKKYTITSEGMKLKNYGDFF VLASDKRIGNLLELVGSDIVSKEDIMEEFNKYDQCRPEISSIVFNLEKWAFDTYPELSARVDRE EKVDFKSILKILLNNKNINKEQSDILRKIRNAFDHNNYPDKGVVEIKALPEIAMSIKKAFGEYA IMK** 